8-2008

\title{
Why biodiversity is important to the functioning of real-world ecosystems
}

JE Duffy

Virginia Institute of Marine Science

Follow this and additional works at: https://scholarworks.wm.edu/vimsarticles

Part of the Ecology and Evolutionary Biology Commons

\section{Recommended Citation}

Duffy, JE, "Why biodiversity is important to the functioning of real-world ecosystems" (2008). VIMS Articles. 1747.

https://scholarworks.wm.edu/vimsarticles/1747

This Article is brought to you for free and open access by W\&M ScholarWorks. It has been accepted for inclusion in VIMS Articles by an authorized administrator of W\&M ScholarWorks. For more information, please contact scholarworks@wm.edu. 


\title{
Why biodiversity is important to the functioning of real-world ecosystems
}

\author{
J Emmett Duffy
}

\begin{abstract}
Controlled experiments have substantially advanced our understanding of the links between changing biodiversity and ecosystem functioning (BEF) in recent years. However, controversy continues regarding the relevance of BEF experiments to the complex ecosystems and large spatial and temporal scales of interest in conservation and management. Here, I address some of the persistent criticisms regarding experimental BEF research and argue that these have been overstated. Contrary to some suggestions, many putative artifacts attributed to experiments render their conclusions about BEF links stronger, rather than weaker. Like other broad ecological concepts, BEF focuses on general patterns, rather than looking at species-level, applied conservation problems. Nevertheless, insights from BEF experiments conducted to date are likely to underestimate, rather than overestimate, the importance of biodiversity to ecosystem functioning and the provision of ecosystem services in the real world. These experiments suggest that managing ecosystems to promote biodiversity can have important practical benefits.
\end{abstract}

Front Ecol Environ 2009; 7(8): 437-444, doi:10.1890/070195 (published online 27 Aug 2008)

$\mathrm{T}$ he mass extinction of species currently underway has generated concern for many reasons, ranging from aesthetic and spiritual to purely commercial. But from the utilitarian perspective that underpins most policy, perhaps the most important concerns involve the potential consequences of species loss for the continued functioning of ecosystems and the services they provide to humanity. This recognition stimulated a rapid growth of research on links between biodiversity and ecosystem functioning $(\mathrm{BEF})$ over the past decade. These studies have generated continuing controversy (eg Huston 1997; Wardle et al. 2000; Leps 2004), leading some reviewers to conclude that the results of BEF experiments are too variable to draw general conclusions (Giller et al. 2004; Thompson and Starzomski 2007). The latter concern has now been largely resolved by two comprehensive meta-

\section{In a nutshell:}

- The dominant influence of individual species (compared with diverse communities) on ecosystem functioning in experimental settings is largely an artifact of their simplified environments and the single response variables considered

- As a result, experiments have probably underestimated the importance of biodiversity to real-world ecosystem functioning

- Suggested discrepancies between diversity-productivity relationships in nature versus those in experiments are largely illusory, and stem from the bidirectional influence between productivity (potential or realized) and diversity

- Several lines of evidence indicate that maintaining multiple ecosystem services over time in a changing world is enhanced by high local and regional diversity

Virginia Institute of Marine Science, The College of William and Mary, Gloucester Point, VA (jeduffy@vims.edu) analyses that examined the results of over 100 experiments and $>400$ measures of biodiversity effects (Balvanera et al. 2006; Cardinale et al. 2006). These analyses revealed evidence that mixtures of species produce more biomass and use more resources, on average, than do single species. This pattern is surprisingly consistent across taxa, trophic levels, and habitats. Even within more realistic, multilevel food webs, experiments show that biodiversity tends to have predictable effects, with prey diversity generally supporting higher predator growth, but lower predator impact on total prey biomass (Duffy et al. 2007).

BEF research has often been justified in the context of understanding the consequences of looming extinction for human welfare. However, in practice, most research has been more narrowly focused, employing small-scale, highly controlled experiments with designs whose relevance to natural ecosystems and realistic extinction scenarios is often unclear. For these reasons, research on BEF links has persistently been criticized, suggesting to some authors that invoking BEF relationships to justify biodiversity conservation may be misleading or counterproductive (Wardle 1999; Srivastava and Vellend 2005; Thompson and Starzomski 2007). In this paper, I argue that many of these criticisms are overstated, and that the experimental evidence for BEF is generally consistent and has important practical implications for conservation and management.

As others have emphasized elsewhere (eg Srivastava and Vellend 2005), discussions of BEF research have sometimes confused scientific concepts (functioning) with value or normative judgments (services). I distinguish an ecosystem property as any aggregate structural variable, ie a measure of the current state of the system, 
such as biomass or soil nitrogen content, and an ecosystem function as any aggregate process, such as production, respiration, or grazing rate. The sign, whether positive or negative, and the magnitude of these variables are neither "good" nor "bad". In contrast, an ecosystem service is a process considered to have some, necessarily subjective, value to humanity. Thus, a diversity-mediated increase in the ecosystem function of primary production can be considered either a service (eg a crop, or the foundation species of a valued ecosystem) or a disservice (eg a eutrophic water body). For the sake of clarity, I refer to changes in any of these aggregate ecosystem variables as ecosystem responses. Most BEF experiments and theory have focused on species richness as the metric of biodiversity, so I follow that usage here, although a growing body of evidence suggests that the influence of biodiversity on ecosystem functioning is broadly similar across levels of organization.

\section{Responses to some criticisms of BEF research}

\section{Criticism 1: Most BEF relationships result from statistical sampling effects, rather than from "true" effects of diversity}

In experiments, diverse mixtures of species can show higher productivity than the average single-species plot, simply because they are more likely to contain the one species that grows best under local conditions, if that species then comes to dominate the plot. This statistical phenomenon has been termed the "sampling effect" (Huston 1997; Tilman et al. 1997). Since, under this hypothesis, functioning is dominated by a single species, it has been considered an artifact, rather than a "true" effect of diversity (Huston 1997; Wardle 1999). From a conservation perspective, even BEF relationships that can be explained by this sampling mechanism are important in showing that species loss can substantially change normal ecosystem functioning (Srivastava 2002). But the question remains: is the sampling effect in fact common and important? Meta-analysis of 111 experiments confirmed that diverse mixtures of species rarely produced more biomass than the most productive single species (Cardinale et al. 2006), a result superficially consistent with the sampling effect.

However, three points caution against accepting this interpretation at face value. First, the failure of polycultures to outperform the best monoculture can result not only from the sampling effect, but also from a combination of positive complementarity (ie resource partitioning or facilitation) and negative selection effects (ie dominance by a poor performer; Loreau and Hector 2001). In fact, experiments with both terrestrial (Hector et al. 2002; Hooper and Dukes 2004) and marine (Bruno et al. 2005) plants found that the failure of diverse assemblages to outperform the best monoculture was indeed due to a combination of negative selection and complementarity, not to the sampling effect. Although this may seem an arcane distinction, it is fundamentally important because this interaction of selection and complementarity allows multiple species to coexist in the community, whereas in the classical sampling effect model (Huston 1997; Tilman et al. 1997), the single best-performing species outcompetes the others, which eventually results in a monoculture. The second point is that the complementary resource use that underlies $\mathrm{BEF}$ relationships is predicted to emerge over time (Pacala and Tilman 2002), yet many experiments have not run for long enough to see complementarity become important. Those that have done so (Tilman et al. 2001; Hooper and Dukes 2004; Stachowicz et al. 2008) found that, over time, the BEF relationship and the importance of complementarity become stronger, and that the number of species required to maximize function increases. These general patterns are confirmed by a recent meta-analysis of 44 experiments (Cardinale et al. 2007; Figure 1). Third, and finally, the sampling effect implicitly focuses on a single response variable, typically plant biomass accumulation. In the context of management and conservation, we are interested in ecosystems that perform multiple functions and services. Even in cases where a single species dominates a given ecosystem process, it is unlikely to dominate all of the processes of interest. Indeed, simulations of empirical data show that, as the number of ecosystem processes we consider increases, redundancy among species decreases and the relationship between species richness and (multivariate) ecosystem functioning grows stronger (Petchey and Gaston 2002b). Recent BEF experiments support this prediction, showing that, even where particular species monocultures can match diverse mixtures for individual ecosystem processes, different species maximize different ecosystem properties. The result is that only the diverse mixture maximizes multiple properties simultaneously, a phenomenon termed "multivariate complementarity" (Duffy et al. 2003; Bracken and Stachowicz 2006; Hector and Bagchi 2007; Gamfeldt et al. 2008; Figure 2). These considerations show that, from the perspective of maintaining integrity of multifunctional ecosystems, the classical argument about the sampling effect in BEF experiments is a red herring, arising from a narrow focus on single response variables and short-term experiments. Maintenance of the multiple functions provided by real, complex ecosystems requires multiple species.

\section{Criticism 2: BEF relationships usually reach an asymptote at very low species richness}

Arguments for the functional importance of biodiversity seem incompatible with the common finding that, in experiments, ecosystem function typically saturates at a species richness much lower than that found in nature (Schwartz et al. 2000). The probable reason for this is that ecosystem processes tend to be most strongly influenced by dominant species (Grime 1998; Polley et al. 
2007). An obvious conclusion would be that very few species are needed to maintain normal ecosystem functioning, but recent research shows that this conclusion is unjustified for several reasons. First, as the previous section showed, the short durations of many previous experiments probably precluded expression of diversity effects. Second, and perhaps more importantly, nearly all BEF experiments to date have focused on a single response variable at a time. But, as discussed above, even where sampling might explain individual ecosystem responses, different species can dominate different ecosystem response variables, so maintaining multiple functions requires more species (Figure 2). Third, most experiments have been conducted in small plots, under highly controlled, homogenized conditions, yet theory predicts that the influence of diversity increases in heterogeneous environments or landscapes (Tilman et al. 1997; Cardinale et al. 2000; Loreau et al. 2003). Recent evidence from several wild, non-experimental systems supports this prediction (Tylianakis et al. 2008; Figures 3, 4). More generally, there is considerable evidence that rare species can make important contributions to ecosystem processes under changing conditions (Lyons et al. 2005). Finally, because of the well-documented relationship between species richness and area, maintenance of a given level of diversity at the local (plot) level depends on a considerably higher regional diversity. Thus, maintaining a given level of local species richness requires conserving a larger number of species at the regional scale. All of these considerations suggest that the apparent saturation of ecosystem function at low species richness is largely an artifact of the homogeneous conditions, short time scales, small plot sizes, and narrow focus of experiments conducted to date. Again, the conclusion is that experiments have underestimated, not overestimated, the importance of biodiversity to the functioning of real, complex ecosystems.

\section{Criticism 3: Experimental diversity gradients bear no resemblance to real-world extinction scenarios}

The artificiality of random assembly in BEF experiments has been noted repeatedly (eg Huston 1997; Srivastava 2002; Giller et al. 2004; Leps 2004). Random assembly designs were used in many early BEF experiments, because they avoid confounding the effects of species richness - the object of most such experiments - with the effects of species composition. Although the first genera-
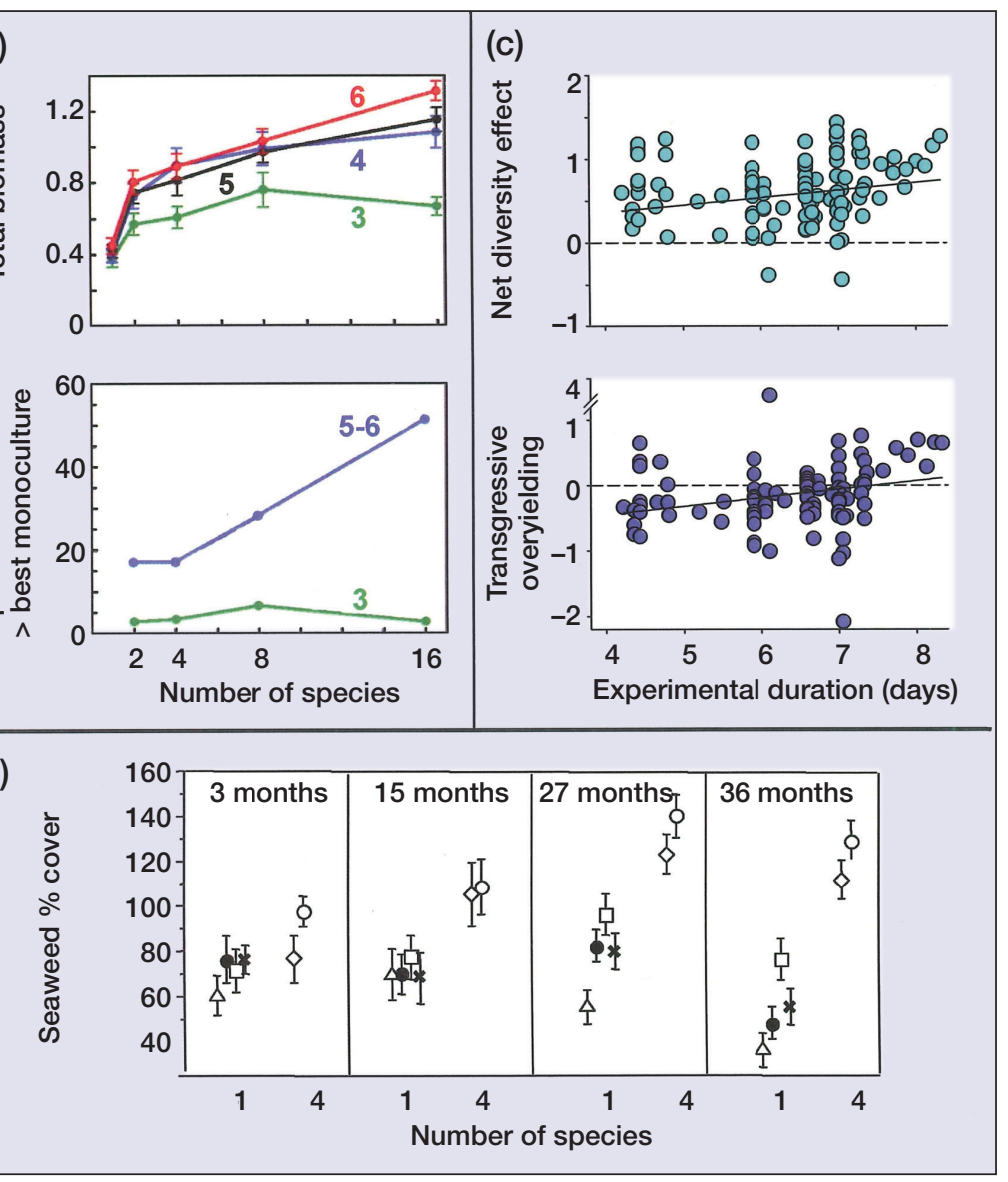

Figure 1. The importance of biodiversity and complementary resource use to plant productivity increases with time. (a) In a grassland experiment, both the magnitude after Tilman et al. 2001). (b) Similarly, in a marine intertidal experiment, enhancement of biomass accumulation by seaweed diversity increased as the experiment matured from 3 months to 3 years ( \pm SE; Stachowicz et al. 2008). c) Quantitative meta-analysis confirms that these examples are not atypical. Among 4 experiments, both the net effect of species richness on production (upper panel) and the magnitude of the diversity effect relative to the most productive monoculture (lower panel) increased with time (adapted from Cardinale et al. 2007).

tion of BEF experiments required these designs to separate richness and complementarity effects (Huston 1997), it has long been recognized that random assembly trades off realism for this precision in interpretation. To remedy this, researchers have used theory (Gross and Cardinale 2005), simulations (Petchey and Gaston 2002a; Ostfeld and LoGiudice 2003; Solan et al. 2004), and experiments (Jonsson et al. 2002; Zavaleta and Hulvey 2004) to explore effects of non-random loss scenarios. These studies confirm the intuitive expectation that order of loss affects ecosystem responses, and most show more specifically that realistic extinction orders have larger effects on ecosystem responses than do random loss sequences. Thus, if existing experimental results can be generalized, they suggest that random loss designs underestimate the ecosystem consequences of diversity loss. Again, conclu- 
(a)

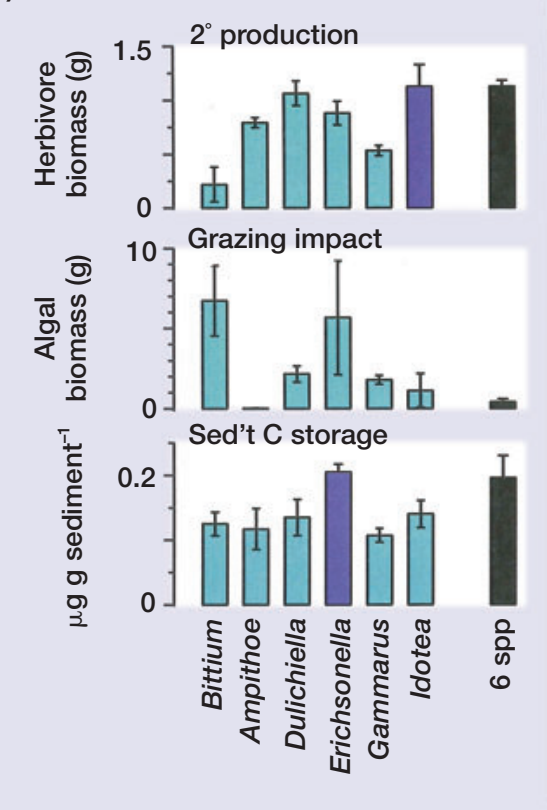

(b)

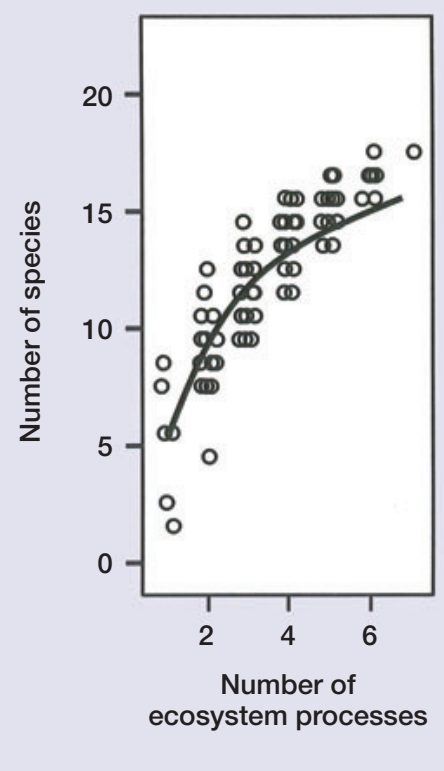

(c)

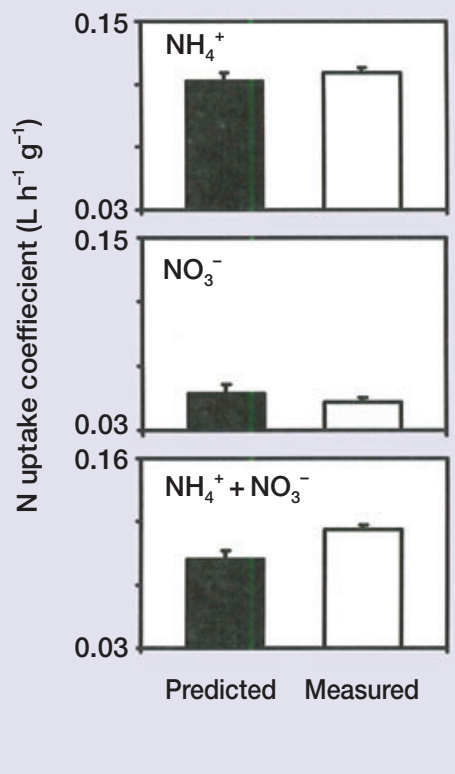

Figure 2. Multifunctional ecosystems require many species. (a) In experimental seagrass systems, different herbivore species maximized different ecosystem properties, but only the diverse assemblage containing all species (black) maximized all simultaneously ( \pm SE; data from Duffy et al. 2003). (b) In grassland experiments, the number of species required to maximize ecosystem functioning increased with the number of ecosystem processes considered (modified from Hector and Bagchi 2007). (c) Similarly, in a seaweed assemblage, uptake of individual nutrients was predictable by summing contributions of individual species (predicted $=$ measured), whereas total nitrogen uptake $\left(\mathrm{NH}_{4}{ }^{+}+\mathrm{NO}_{3}^{-}\right)$was greater than predicted from individual species contributions ( \pm SE; modified from Bracken and Stachowicz 2006).

sions about the functional consequences of diversity loss from random assembly experiments appear conservative.

\section{Criticism 4: Diversity may enhance productivity in experiments, but the opposite pattern is found in nature}

It has been suggested by some authors that the frequently negative relationship between resource availability ("productivity") and plant diversity in nature contradicts the results of BEF experiments (Huston 1997; Wardle et al. 2000). However, others have shown that this contradiction is illusory, stemming from conflation of two distinct phenomena that are both referred to as "productivity". The apparent discrepancy can be explained by the fact that relationships between species diversity and "productivity" are bidirectional (Loreau et al. 2001). Withinhabitat diversity generally increases as resource availability (productivity potential) rises from low to moderate levels, because the more favorable environment allows species to persist that could not do so with less abundant resources. However, as resources increase in abundance, intensifying competition reduces diversity, illustrating the "paradox of enrichment". Thus, cross-site comparisons over the higher end of this resource availability range often show negative relationships between environmental "productivity" (eg nutrient supply) and plant diversity (reviewed by Huston 1997). Such comparisons consider a gradient in the abiotic environment and assume implicitly that a large regional pool of species is available to colonize all sites. In this situation, one expects a negative correlation between aggregate biomass, which reflects carrying capacity and local diversity. However, this relationship occurs because variance in resource availability (environmental "productivity") is determining diversity, rather than vice versa.

In contrast, BEF experiments seek implicitly to address the opposite phenomenon, the consequences of global or regional species loss from a system in which resources and the abiotic environment are held constant. Thus, surveys and experiments test different causal directions of the biodiversity-productivity relationship. Surveys of unmanipulated systems test how local diversity responds to changing resource availability ("productivity"), whereas experiments test how productivity (biomass production per unit time) responds to changing species diversity. Importantly, the two phenomena are not mutually exclusive: at any given site along a resource gradient, resource availability will determine which, and how many, species from the available pool persist in the community (ie diversity). However, as theory and experiments show, the actual production of plant biomass at that site is likely to be lower when the pool of species available to colonize it is reduced (Loreau et al. 2001). Thus, the patterns in nature and in experiments are not contradictory. Moreover, the apparent discrepancy between experi- 
ments and field patterns for land plants is not seen in some marine benthic systems, where the greater impacts of diverse assemblages on invaders and on prey are consistent with patterns in the field (Stachowicz et al. 2002; Byrnes et al. 2006; see also Figure 3).

\section{Criticism 5: Biodiversity effects, when present, are probably minor as compared with resource supply and other drivers of ecosystem processes}

At regional or continental scales, plant production is closely correlated with resource availability. How much extra variance, if any, is explained by plant diversity? Few experiments have explicitly compared the quantitative importance of changing diversity within trophic levels to that of nutrient loading, cascading predator effects, and other factors. The few that have done so suggest that changing biodiversity within trophic levels can be of comparable importance to realistic ranges of bottom-up and top-down forcing. In the most comprehensive example, changing species richness of herbivorous pond snails had comparable or greater effects on a range of ecosystem processes than did a fourfold change in nutrient supply or exclusion of predators (Wojdak 2005). Experiments in seagrass ecosystems showed similar results; effects of changing herbivore diversity were comparable in magnitude to those of cascading predator effects (Duffy et al. 2005) and often greater than those of changing light availability or seasonal forcing (Spivak et al. 2007; Duffy et al. unpublished data). Earlier experiments that manipulated both nutrients and plant diversity (Fridley 2002) concluded that nutrient effects overwhelmed diversity effects, but used large ranges in nutrient supply and relatively modest ranges in diversity. Again, cases where field patterns and experimental results are concordant (Stachowicz et al. 2002; Byrnes et al. 2006) further support the importance of diversity in some real ecosystems. Thus, the few available experimental data suggest that changing diversity within trophic levels has non-trivial consequences, even within the context of dynamic ecosystems impacted by other factors.

\section{Criticism 6: Effects of declining biodiversity on ecosystem functioning are indirect and weaker than direct impacts of habitat destruction}

This is a compelling argument for terrestrial systems, where habitat destruction is the major threat to ecosystems (Srivastava 2002; Srivastava and Vellend 2005). It arguably carries less weight in the oceans, where the greatest threat to biodiversity is direct overharvesting (Figure 5). Even on land, this argument applies more to short-term than to long-term effects of biodiversity loss. Clearly, habitat destruction, which involves both biodiversity loss and abiotic habitat alteration, will usually have stronger impacts on ecological processes than will species loss alone. And, in practice, focusing conserva-
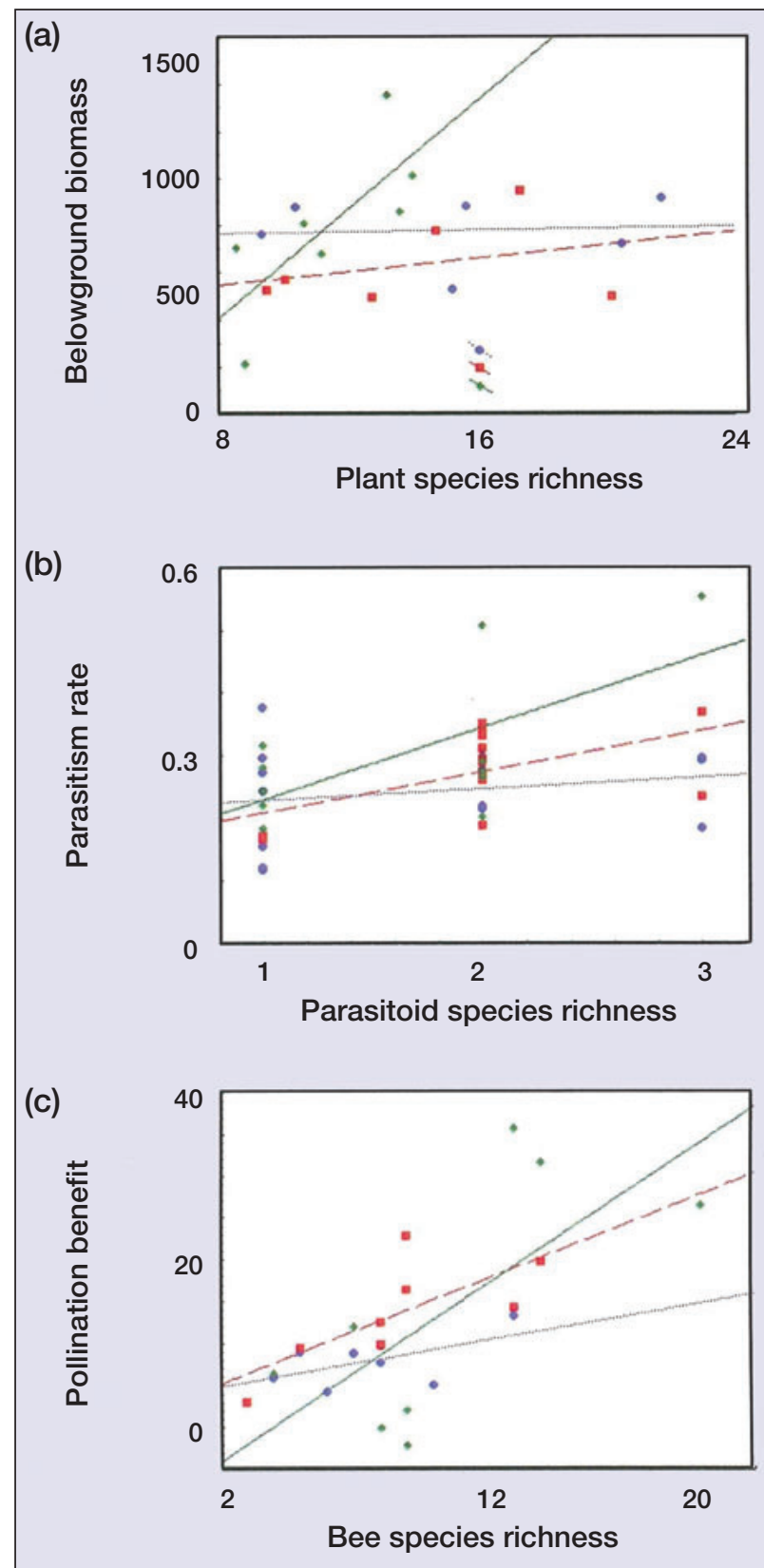

Figure 3. The influence of biodiversity on ecosystem processes increases with environmental heterogeneity in wild, nonexperimental systems. More spatially heterogeneous environments exhibit stronger relationships between (a) plant richness and plant biomass production in a European grassland; (b) natural enemy richness and rates of parasitism on wasps in coastal Ecuador; and (c) wild bee richness and pollination effectiveness on coffee plantations in Indonesia. In each panel, data are divided into three classes of environmental heterogeneity: low (blue symbols, dotted line), medium (red symbols, dashed line), and high (green symbols, solid line). After Tylianakis et al. (2008).

tion effort on protecting habitat is likely to conserve both biodiversity per se and the abiotic and structural components necessary to sustain it. Nevertheless, biodiversity loss remains uniquely important because, within limits, 

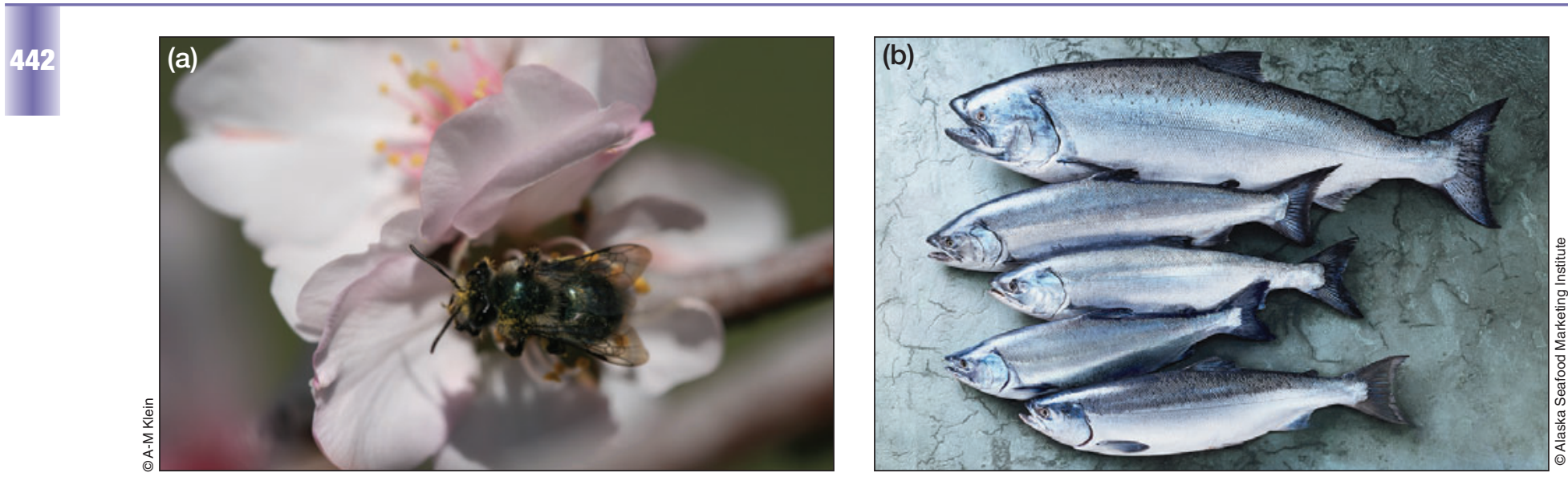

Figure 4. Examples in which species or genetic diversity have been shown to enhance important ecosystem services in the real world. (a) Crop pollination is often more effective in areas with higher native bee diversity (Klein et al. 2003). The picture shows the native bee Andrena cerasifolii visiting an almond flower in California. (b) Harvest of salmon in Alaska has been relatively stable over recent decades, despite strong fluctuations in individual stocks, because ecologically differentiated stocks respond differently to climate change and other environmental variation (Hilborn et al. 2003).

degraded habitats can potentially be restored, whereas extinction of species is permanent. In Costa Rica, for example, forest cover had declined by $80 \%$ before reclamation and tree planting brought it back above $50 \%$. Yet, any species lost to extinction during that deforestation cannot be reclaimed. Thus, over the long term and across systems, conserving species is probably as important as preventing habitat loss.

\section{Conclusions}

Experimental BEF research has now matured sufficiently to allow us to conclude with some confidence that, on average, higher species richness increases biomass accu-

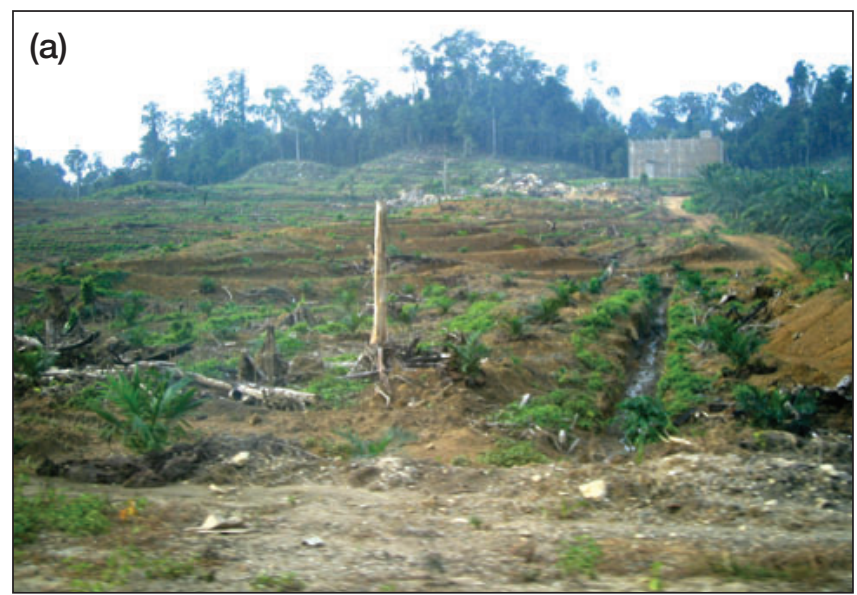

Figure 5. Drivers of environmental change differ among systems, with implications for how biodiversity affects ecosystem processes. (a) In terrestrial systems, such as Southeast Asian rainforests, habitat loss and degradation drive changes in ecosystem processes both directly and indirectly, through their impacts on biodiversity. (b) In the ocean, overharvesting is a pervasive human impact and is likely to influence ecosystem functioning indirectly, through the changing interactions that stem from loss or ecological extinction of species. mulation and resource use within trophic levels, and decreases variance in those responses through time. In many cases, these effects on structure and functioning also have implications for ecosystem services of value to humanity. Although the real-world implications of this $\mathrm{BEF}$ research have often been questioned, the issues considered here suggest that experimental results generally underestimate the influence of biodiversity on functioning of complex ecosystems and, thus, are conservative. Maintenance of the multiple ecosystem services that support society over extended time scales in a changing world will probably require a much greater number of species than are typically used in BEF experiments. Thus, management to conserve biodiversity should often pro-

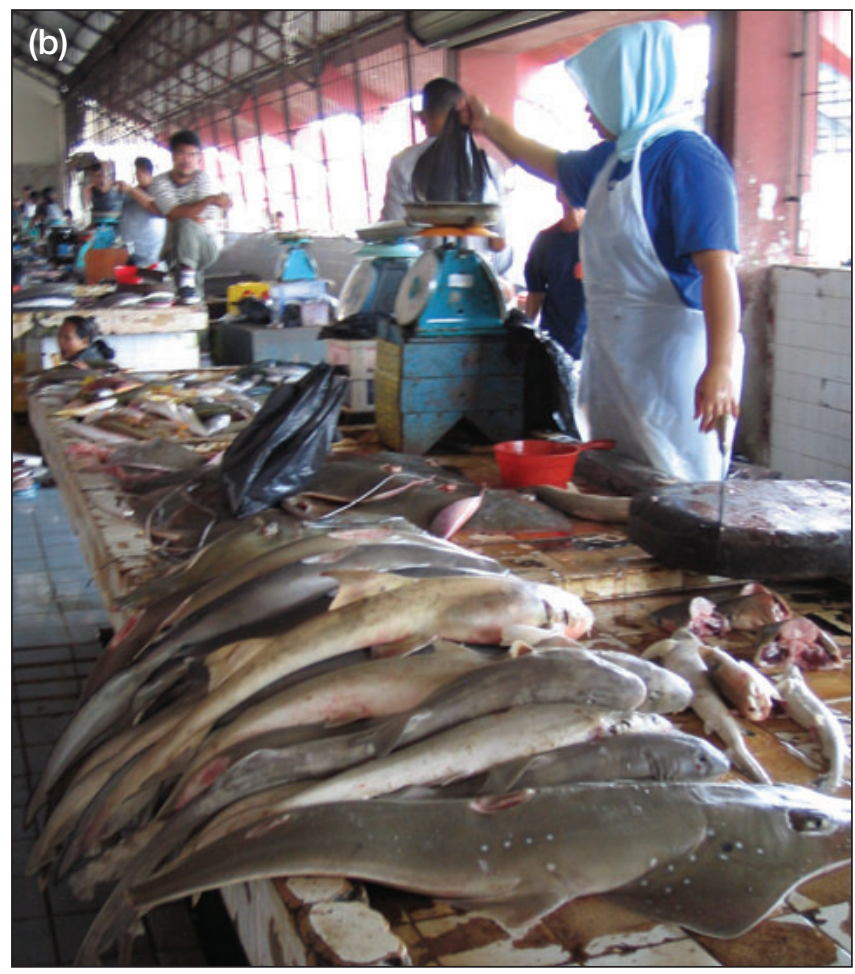


vide utilitarian benefits, which serve as one among the several rationales for conservation. Palumbi et al. (2009) have made essentially the same case in the context of implementing ecosystem-based management (EBM) of marine fisheries. EBM has been federally mandated, in part because of frequent failure of, and conflict involved in, management efforts focusing on single fishery species. Palumbi et al. argue that ecosystems are so complex that we will rarely understand their workings mechanistically, so that maintenance of biodiversity may serve as a useful proxy for a system state that supplies the multiple ecosystem services of interest. Thus, managing to maximize biological diversity (however defined) may be a workable way to ensure long-term maintenance of an acceptable balance among the sometimes competing demands for various ecosystem services. This is an example where a broad-brush approach, informed by BEF research, may actually prove more effective in conservation than one based on the biology of individual species. Clearly, managing for biodiversity is not a substitute for identifying key ecosystem service providers, community interactions, and environmental drivers within particular systems (Kremen 2005). However, by providing a conceptual framework based on general principles, it can provide a complementary approach.

Previous research and controversies offer several points of guidance for future work and application. One way to make BEF research more realistic and applicable is to focus on key traits of organisms - specifically, the covariance between traits that predispose species to extinction and traits that influence ecosystem properties (Gross and Cardinale 2005). There is a growing body of empirical data on extinction sequences and extinction traits (eg Purvis et al. 2000; Dulvy et al. 2004) and a growing interest in how traits influence vital ecosystem processes. An important step involves uniting these bodies of knowledge with community ecological theory to build predictive models of how realistic extinction scenarios will influence ecosystem processes and services (Srivastava 2002; Kremen 2005). Since one of the most consistent extinction predictors is high trophic level, practical application of BEF research will also require a more intensive focus on effects of changing diversity in multitrophic systems (Duffy et al. 2007). In the meantime, we have learned enough from theory and experiments about how biodiversity affects ecosystem functioning to justify a general goal of conserving biodiversity for utilitarian as well as other reasons.

\section{Acknowledgements}

The author is grateful to the BIOMERGE group for stimulating discussions, to M Bracken, J Bruno, M Schwartz, and J Stachowicz for comments that improved the manuscript, to A-M Klein and the Alaska Seafood Marketing Institute for permission to reproduce photos, and to the NSF (OCE-0623874) for support.

\section{References}

Balvanera P, Pfisterer AB, Buchmann N, et al. 2006. Quantifying the evidence for biodiversity effects on ecosystem functioning and services. Ecol Lett 9: 1146-56.

Bracken MES and Stachowicz JJ. 2006. Seaweed diversity enhances nitrogen uptake via complementary use of nitrate and ammonium. Ecology 87: 2397-2403.

Bruno JF, Boyer KE, Duffy JE, et al. 2005. Effects of macroalgal species identity and richness on primary production in benthic marine communities. Ecol Lett 8: 1165-74.

Byrnes J, Stachowicz JJ, Hultgren KM, et al. 2006. Predator diversity strengthens trophic cascades in kelp forests by modifying herbivore behaviour. Ecol Lett 9: 61-71.

Cardinale BJ, Nelson K, and Palmer MA. 2000. Linking species diversity to the functioning of ecosystems: on the importance of environmental context. Oikos 91: 175-83.

Cardinale BJ, Srivastava DS, Duffy JE, et al. 2006. Effects of biodiversity on the functioning of trophic groups and ecosystems. Nature 443: 989-92.

Cardinale BJ, Wright JP, Cadotte MW, et al. 2007. Impacts of plant diversity on biomass production increase through time because of species complementarity. P Natl Acad Sci USA 104: $18123-28$.

Duffy JE, Cardinale BJ, France KE, et al. 2007. The functional role of biodiversity in ecosystems: incorporating trophic complexity. Ecol Lett 10: 522-38.

Duffy JE, Richardson JP, and Canuel EA. 2003. Grazer diversity effects on ecosystem functioning in seagrass beds. Ecol Lett 6: 637-45.

Duffy JE, Richardson JP, and France KE. 2005. Ecosystem consequences of diversity depend on food chain length in estuarine vegetation. Ecol Lett 8: 301-09.

Dulvy NK, Ellis JR, Goodwin NB, et al. 2004. Methods of assessing extinction risk in marine fishes. Fish Fisher 5: 255-76.

Fridley JD. 2002. Resource availability dominates and alters the relationship between species diversity and ecosystem productivity in experimental plant communities. Oecologia 132: 271-77.

Gamfeldt L, Hillebrand H, and Jonsson PR. 2008. Multiple functions increase the importance of biodiversity for overall ecosystem functioning. Ecology 89: 1223-31.

Giller PS, Hillebrand H, Berninger UG, et al. 2004. Biodiversity effects on ecosystem functioning: emerging issues and their experimental test in aquatic environments. Oikos 104: 423-36.

Grime JP. 1998. Benefits of plant diversity to ecosystems: immediate, filter and founder effects. J Ecol 86: 902-10.

Gross K and Cardinale BJ. 2005. The functional consequences of random vs ordered species extinctions. Ecol Lett 8: 409-18.

Hector A and Bagchi R. 2007. Biodiversity and ecosystem multifunctionality. Nature 448: 188-96.

Hector A, Bazeley-White E, Loreau M, et al. 2002. Overyielding in grassland communities: testing the sampling effect hypothesis with replicated biodiversity experiments. Ecol Lett 5: 502-11.

Hilborn R, Quinn TP, Schindler DE, and Rogers DE. 2003. Biocomplexity and fisheries sustainability. P Natl Acad Sci USA 100: 6564-68.

Hooper DU and Dukes JS. 2004. Overyielding among plant functional groups in a long-term experiment. Ecol Lett 7: 95-105.

Huston MA. 1997. Hidden treatments in ecological experiments: re-evaluating the ecosystem function of biodiversity. Oecologia 110: 449-60.

Jonsson M, Dangles O, Malmqvist B, and Guerold F. 2002. Simulating species loss following perturbation: assessing the effects on process rates. P Roy Soc Lond B Bio 269: 1047-52.

Klein AM, Steffan-Dewenter I, and Tscharntke T. 2003. Fruit set of highland coffee increases with the diversity of pollinating bees. P Roy Soc Lond B Bio 270: 955-61.

Kremen C. 2005. Managing ecosystem services: what do we need to 
know about their ecology? Ecol Lett 8: 468-79.

Leps J. 2004. What do the biodiversity experiments tell us about consequences of plant species loss in the real world? Basic Appl Ecol 5: 529-34.

Loreau M and Hector A. 2001. Partitioning selection and complementarity in biodiversity experiments. Nature 412: 72-76.

Loreau M, Mouquet N, and Gonzalez A. 2003. Biodiversity as spatial insurance in heterogeneous landscapes. P Natl Acad Sci USA 100: 12765-70.

Loreau M, Naeem S, Inchausti P, et al. 2001. Biodiversity and ecosystem functioning: current knowledge and future challenges. Science 294: 804-08.

Lyons KG, Brigham CA, Traut BH, and Schwartz MW. 2005. Rare species and ecosystem functioning. Conserv Biol 19: 1019-24.

Ostfeld RS and LoGiudice K. 2003. Community disassembly, biodiversity loss, and the erosion of an ecosystem service. Ecology 84: 1421-27.

Pacala S and Tilman D. 2002. The transition from sampling to complementarity. In: Kinzig AP, Pacala SW, and Tilman D (Eds). The functional consequences of biodiversity. Empirical progress and theoretical extensions. Princeton, NJ: Princeton University Press.

Palumbi SR, Sandifer PA, Allan JD, et al. 2009. Managing for ocean biodiversity: creating a national biodiversity conservation agenda to sustain marine ecosystem services. Front Eco Environ 7: 204-11.

Petchey OL and Gaston KJ. 2002a. Extinction and the loss of functional diversity. P Roy Soc Lond B Bio 269: 1721-27.

Petchey OL and Gaston KJ. 2002b. Functional diversity (FD), species richness and community composition. Ecol Lett 5: 402-11.

Polley HW, Wilsey BJ, and Derner JD. 2007. Dominant species constrain effects of species diversity on temporal variability in biomass production of tallgrass prairie. Oikos 116: 2044-52.

Purvis A, Gittleman JL, Cowlishaw G, and Mace GM. 2000. Predicting extinction risk in declining species. P Roy Soc Lond B Bio 267: 1947-52.

Schwartz MW, Brigham CA, Hoeksema JD, et al. 2000. Linking biodiversity to ecosystem function: implications for conservation ecology. Oecologia 122: 297-305.

Solan M, Cardinale BJ, Downing AL, et al. 2004. Extinction and ecosystem function in the marine benthos. Science 306 : $1177-80$.

Spivak AC, Canuel EA, Duffy JE, and Richardson JP. 2007. Topdown and bottom-up controls on sediment organic matter composition in an experimental seagrass ecosystem. Limnol Oceanogr 52: 2595-2607.

Srivastava DS. 2002. The role of conservation in expanding biodiversity research. Oikos 98: 351-60.

Srivastava DS and Vellend M. 2005. Biodiversity-ecosystem function research: is it relevant to conservation? Annu Rev Ecol Evol Syst 36: 267-94.

Stachowicz JJ, Fried H, Osman RW, and Whitlatch RB. 2002. Biodiversity, invasion resistance, and marine ecosystem function: reconciling pattern and process. Ecology 83: 2575-90.

Stachowicz JJ, Graham M, Bracken MES, et al. 2008. Diversity enhances cover and stability of seaweed assemblages: the role of heterogeneity and time. Ecology 89: 3008-19.

Thompson R and Starzomski BM. 2007. What does biodiversity actually do? A review for managers and policy makers. Biodivers Conserv 16: 1359-78.

Tilman D, Lehman CL, and Thomson KT. 1997. Plant diversity and ecosystem productivity: theoretical considerations. P Natl Acad Sci USA 94: 1857-61.

Tilman D, Reich PB, Knops J, et al. 2001. Diversity and productivity in a long-term grassland experiment. Science 294: 843-45.

Tylianakis JM, Rand TA, Kahmen A, et al. 2008. Resource heterogeneity moderates the biodiversity-function relationship in real world ecosystems. PLoS Biol 6: 947-56.

Wardle DA. 1999. Is "sampling effect" a problem for experiments investigating biodiversity-ecosystem function relationships? Oikos 87: 403-07.

Wardle DA, Huston MA, Grime JP, et al. 2000. Biodiversity and ecosystem function: an issue in ecology. B Ecol Soc Am 81: 235-39.

Wojdak JM. 2005. Relative strength of top-down, bottom-up, and consumer species richness effects on pond ecosystems. Ecol Monogr 75: 489-504.

Zavaleta ES and Hulvey KB. 2004. Realistic species losses disproportionately reduce grassland resistance to biological invaders. Science 306: 1175-77.

\section{TAKE THIS JOURNAL TO YOUR LIBRARIAN, PLEASE}

Are you enjoying this issue of Frontiers?

If your library had a subscription, colleagues and students could enjoy it too.

Please consider recommending Frontiers in Ecology and the Environment to your library.

Clip or copy the form below.

Thank you for your support.

Library Recommendation Form
To Acquisition Librarian, Serials
From
I recommend the library subscribe to: Frontiers in Ecology and the Environment (ISSN 1540-9295)
To request a free sample issue of Frontiers in Ecology and the Environment, email Eric Gordon at eric@esa.org.
Order Frontiers by contacting ESA Headquarters at (202) 833-8773, online at www.esa.org, or through your subscription agent.

